\title{
Sparks continue to fly in low-level radiation row
}

\section{David Dickson describes a conflict in paradigms behind differing interpretations of the health hazards of nuclear power}

Two and a half months after the National Academy of Sciences submitted to the Environmental Protection Agency the "final draft" of a long-awaited report on the biological effects of ionising radiation, an ad hoc committee within the academy is still meeting to re-write the most controversial section of the report, that discussing the appropriate model for interpreting the dose-response relationship for low levels of human exposure.

With public concern at the possible health hazards of nuclear power fuelled by the recent accident at Three Mile Island - and the nuclear industry no less concerned about meeting the costs of a possible tightening of occupational exposure levels - the issue is inevitably a hotlydebated one. Hopes that the temperature might be reduced by referring the issue to the academy, however, have been frustrated by a dispute over the interpretation of scientific evidence as heated as the public controversy outside.

The scientific dispute emerged briefly into public view at a press conference in May, when presentation of the draft conclusions of the academy study was accompanied by a strongly-worded minority statement claiming that the report's conclusions could lead to "detrimental apprehension" over radiation hazards; when additional members of the drafting committee indicated their own reservations, academy president Dr Philip Handler decided that the disputed section should be re-written.

Controversy already surrounds two other academy reports on politically sensitive issues, one on methods of nuclear waste management which was withheld from publication partly at the request of the Department of Energy, the other a massive study on energy policy which is already two years behind schedule. And Dr Handler has now announced that top NAS officials will be taking a close look at procedures for handling such issues over the summer "to see that these type of problems don't happen again."

Concern over the health effects of radiation is as old as knowledge of rad 1 tion itself. Until the mid-1960s, the main issue of controversy was whether a threshold exists below which radiation can be assumed to have negligible effect; since then, most scientists have accepted that there is probably no such threshold, and the debate has been over the shape of the dose-response relationship at low levels of exposure.

In a report in 1972, the academy's Committee on the Biological Effects of Radiation (BEIR) suggested that a linear hypothesis, extrapolating backwards from the known relationship at high levels, was the most appropriate to adopt for regulatory purposes - given all the uncertainties involved - and this has been accepted by various standard setting bodies.

However, this hypothesis has been attacked from both sides. Suporters of the nuclear industry claim that it is too restrictive, considerably overstating the risks; on the other hand studies of nuclear workers and others have been reported which, industry critics claim, show even existing exposure levels to be too high.

The BEIR committee, in its new report, sticks to the linear hypothesis as the most "prudent" assumption. Within the committee, however, a fierce battle has raged over whether, and if so to what extent, this assumption overstates the "true" risk. Both sides in the dispute agree that there is insufficient human data to provide statistically valid risk estimates for exposures of less than about 10 rads; where they disagree, with almost religious fervour, is what type of models can be used to fill the gap.

Supporters of the linear hypothesis tend to rely predominantly on epidemiological and statistical arguments. They claim, firstly that there is sufficient evidence from other studies, such as the effects of the medical uses of radiation, to make the linear hypothesis plausible; and secondly that the lack of human data makes it statistically impossible to reach any more precise assessment

Their opponents, in contrast, tend to rely more heavily on radiobiological data obtained from studies of the effects of radiation on lower organisms. In the minority report attached to the draft of the committee's report, it is stated that "even if the linear model were in fact to afford a substantially better fit to epidemiological data, this would be insufficient justification for rejection of models that are consistent with a vast body of radiobiological evidence."

According to the latter arguments, a more appropriate dose-response model (at least for "low energy transfer" radiation, such as gamma rays) would be a quadratic one, possibly with a linear component. The linear hypothesis, they suggest, should only be accepted as an upper limit, with suitable recognition of a low limit of equal validity. "It should then be stated that the true risk is between these limits, and very likely near the lower limit"'.

Radiobiological data is also given greater prominence in deliberations within the National Council for Radiobiological Protection, a body which, although private, has been attacked by critics for its links to the nuclear establishment. Dr Victor Bond, for example, chairman of an NCRP committee which is soon to produce a report on low level radiation expected to reach different conclusions to the BEIR committee, told a Congressional committee last month that there were "good biological reasons" to support the lower estimates.

Dr Bond referred in particular to studies such as those carried by Dr Harald Rossi, one of the most outspoken critics of the linear hypothesis on the BEIR committee, and colleagues at the Columbia University College of Physicians and Surgeons in New York, on genetic changes in cells of the plant Tradescantia. "Radiobiology in simple systems is important to the establishment of the most-probable doseeffect relationships for the human being" he said, adding that the linear hypothesis for low level radiation was "biologically unsubstantiated".

Nowhere is the difference between the supporters and the critics of the linear hypothesis more marked, however, than in their different interpretations of studies on survivors of the atomic bombs dropped on Hiroshima and Nagasaki.

The critics point for support of their curvilinear hypothesis to studies of the mortality rates from all forms of cancer carried out between 1950 and 1974 on 80,000 survivors in the two cities. Concentrating in particular on the Nagasaki mortality data, this reveals an effect "about ten times lower than that based on proportional projections from persons receiving high X-ray doses", according to Dr Edward Webster of Harvard Medical School, co-author with Dr Rossi of the original minority report.

Supporters of the linear hypothesis, however, look at the Japanese data differently. They criticise the mortality data for its lack of statistical precision (in particular in the light of uncertainties over the relative effects of gamma and neutron components), arguing that "it is difficult to define a functional form in the dose reponse relationship" and that a linearquadratic curve "is not demonstrably superior to a simple linear fit."

As an alternative, the original draft of the report suggests that it is more useful to look at data on cancer incidence rather than on mortality; and that a registry of solid tumours among Nagasaki survivors - evidence whose validity is questioned by the critics - supports their general hypothesis.

A further dimension to the dispute and, one that some argue, is largely fuelling it - has been a sharp difference in attitude towards the nuclear power industry. Dr Edward Radford of Pittsburgh University, chairman of the BEIR committee, has made little secret of his personal views that current permitted exposure levels for nuclear workers are unnecessarily and perhaps dangerously high, suggesting that exposure levels be 
reduced by a factor of up to ten.

"The purpose of requiring more restrictive occupational exposure limits is to provide clear design criteria to allow engineers to design facilities to meet these kinds of standards, rather than rely on the somewhat nebulous and legally dangerous to the industry "as low as reasonably achievable' concept," he says.

The dissenting group on the BEIR committee has made it equally clear that it feels too restrictive exposure levels could place an unnecessarily heavy burden on the nuclear industry. The original minority report warns that overestimates of radiation hazard could result in "serious detriment" to national energy policy. "If the guide line levels were reduced in the way
[Radford] wants them, there would not be any nuclear industry at all' ' one committee member has been quoted as saying.

The BEIR committee dispute has been characterised as a conventional scientific disagreement. "Such controversies have existed within the scientific community since time immemorial. We will truly be in trouble when scientists passively accept each other's work without challenge,"'says Dr Sidney Marks of the Battelle Memorial Institute's Pacific North-West Laboratory.

In this case, however, the incentive has been primarily provided not by a desire for knowledge, but by a specific regulatory need; and the resulting impasse therefore carries both scientific and political dimensions. Initially the academy had hoped that this could be accommodated in the minority report; however when it emerged that over half of the BEIR committee's somatic effects subcommittee shared the reservations about the degree of support given to the linear hypothesis, it was decided that a redrafting of the whole section to produce "a more balanced expression of differing interpretations" would be more appropriate.

The new version will, it is hoped, be ready for re-submission to the full committee within a few weeks. The academy still says that "dissenting views will be published in the final report"; so whatever is agreed is unlikely to be taken as the last word.

\section{US scientists warn of environmental dangers from synthetic fuels}

As President Carter was preparing the details of a major national programme to stimulate the production of synthetic fuels, announced in his energy speech last Sunday, the Council of Environmental Quality released a report warning that a rapid increase in the use of synthetic fuels could have serious environmental consequences through speeding up the accumulation of $\mathrm{CO}_{2}$ in the atmosphere (see also page 189).

Synthetic fuels, previously a relatively unfashionable area of research, have suddenly been receiving the enthusiastic attention both of the President and of the US Congress.

Despite wide uncertainties over both economic and technical viability, the House of Representatives has already passed a bill authorising a crash development programme aimed at a target of producing 2 million barrels of synthetic fuel a day by the year 1990. And in his energy speech, delivered after almost two weeks of closeted discussion with his top advisers, President Carter proposed a programme that would develop America's alternative fuel sources from coal, oilshale, plant products and the Sun to replace 2.5 million barrels a day of imported oil by 1990 .

However both environmentalists and scientists have expressed concern at the environmental implications of such programmes, urging the President to concentrate on means for achieving energy conservation rather than the search for substitute fuels.

In a report to the $C E Q$, the four scientists say that the production of $\mathrm{CO}_{2}$ resulting from the use of synthetic fuels (such as gas or oil) made from coal is almost $50 \%$ higher than the $\mathrm{CO}_{2}$ emissions resulting from the production of energy directly from coal, and twice as high as the result of obtaining an equivalent amount of energy from natural gas.

"It is our conviction that an appropriate reaction to the mounting worldwide squeeze on supplies of energy requires consideration of the $\mathrm{CO}_{2}$ problem as an intrinsic part of any proposed policy on energy," the four scientists say.

Environmental groups have warned the President about other potentially damaging aspects of a massive synthetics fuels programmes, ranging from the disruption caused by the construction of large production plants to the creation of large quantities of carcinogenic substances.

In a letter sent to the President last week, five such groups urged that he not allow himself to be caught up in what they described as a "synfuel panic", and consider lower-cost conservation programmes as an alternative to a massive commitment to synthetic fuels.

Many of the environmental risks associated with such a commitment were "unacceptable", the groups said in their letter; emphasis should rather be placed on more solar development programmes, less costly programmes for synfuel development, and more oil and gas exploration.

Support for such a policy also came from a different direction, namely a study prepared by the Harvard Business School, soon to be published by Random House under the title "Energy Future". According to this study, the need to constrain oil imports is much greater than most economists and energy analysts have realised, since the political and other costs of dependence on a few producing countries has to be included on top of the market price for oil.

The Harvard study suggests a diverse national energy policy encouraging modest growth in the use of coal, some reliance on nuclear power, and continued efforts to develop synthetic fuels; however it argues that in the current political climate, a stepped-up programme to accelerate conservation and solar energy would prove far more rewarding than any other energy path.

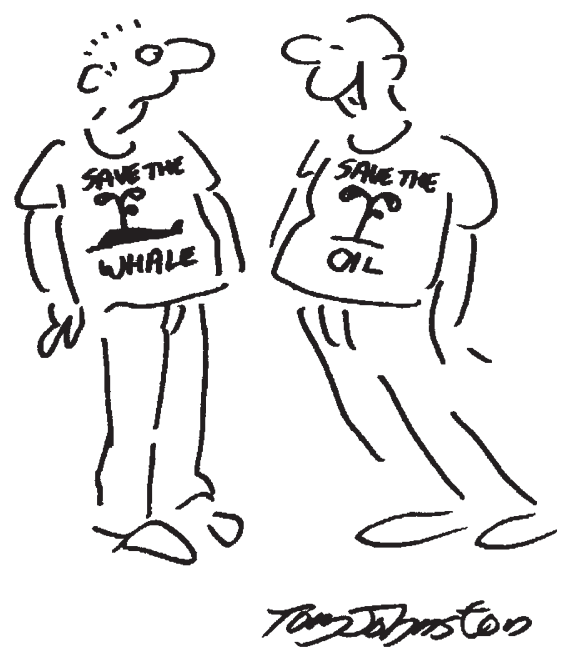

The environmental hazards associated with a major synthetic fuels programme were also covered by a report published last week by the Department of Energy's Office of Technology Impacts. Although the report says that it should be possible to find acceptable sites for large synthetic fuels production plants, it warns that successful commercialisation does have environmental risks, and that stringent environmental controls, management practices and "permitting conditions" should be maintained.

The Department report says that deployment of synthetic liquid facilities on an accelerated schedule to 1990 appears feasible in terms of current environmental constraints, although a target of 2 million barrels a day, rather than 500,000 , would bring "rapid siting difficulties".

In reaching its conclusion, the report says there is some risk that environmental research and development programmes cannot fully satisfy all existing and expected regulatory demands, but that these risks should be known by 1985 , and it is expected that appropriate control adjustments can be made.

"Reduction of these uncertainties requires refocusing of environmental research and assessment programmes to aggressively address these areas", the report says.

David Dickson 